\title{
RHINOLOGY
}

\section{Clinical comparison of the efficacy of spirulina platensis and cetirizine for treatment of allergic rhinitis}

\author{
Studio comparativo di efficacia sulla spirulina platensis e cetirizina nel trattamento \\ della rinite allergica
}

\author{
Morteza Nourollahian¹, Bashir Rasoulian'1, Attaallah Gafari¹, Majid Anoushiravani², Farahzad Jabari ${ }^{1}$, Mehdi Bakhshaee ${ }^{1}$ \\ ${ }^{1}$ Sinus and Surgical Endoscopic Research Center, Emmam Reza Hospital, Faculty of Medicine, Mashhad University of Medical Sciences, \\ Mashhad, Iran; ${ }^{2}$ School of Persian and Complementary Medicine, Department of Persian medicine, Mashhad University of Medical \\ Sciences, Mashhad, Iran; ${ }^{3}$ Allergy Research Center, School of Medicine, Mashhad University of Medical Sciences, Mashhad, Iran
}

\begin{abstract}
SUMMARY
The aim of this study is to compare the efficacy provided by spirulina platensis and cetirizine for treatment of allergic rhinitis (AR). A randomised controlled clinical trial was performed on 53 patients with AR divided into experimental and control groups in an accredited tertiary academic centre. Subjects in the experimental group were treated with spirulina ( $2 \mathrm{~g}$ per day) and the control group was treated with cetirizine (10 mg per day) for 2 months. Symptoms were assessed based on a standard questionnaire and inflammatory mediators, and the results were compared before and after treatment. There were 23 men and 30 women with a mean age of 26.75 years (SD 9.26; range 8-58). The differences between the two groups in terms of age and gender were not significant. There was no significant difference between the two groups in clinical presentations before the intervention $(\mathrm{P}>0.05)$. The prevalence of rhinorrhoea $(\mathrm{P}=0.021)$, nasal obstruction $(\mathrm{P}=0.039)$ and smell reduction $(\mathrm{P}=0.030)$ in the experimental group improved significantly compared to those seen in the control group after intervention. Sleep condition, daily working and social activity improved significantly in the experimental group $(\mathrm{P}<0.05)$. Furthermore, there was no significant difference between groups regarding inflammatory mediators before treatment; however, after 1 month of treatment, the levels of interleukin (IL)-1 $\alpha$ $(\mathrm{P}<0.001), \mathrm{IL}-1 \beta(\mathrm{P}<0.001)$ and IL-4 $(\mathrm{P}=0.008)$ were all significantly lower, and IL-10 levels were significantly higher in the experimental group, compared to those in the control group. In conclusion, spirulina is more effective than cetirizine in improving cardinal symptoms of AR patients. Furthermore, spirulina can be considered as an alternative treatment in patients with AR.
\end{abstract}

KEY WORDS: allergic rhinitis, therapeutics, medical therapy of chronic rhinosinusitis, spirulina

\section{RIASSUNTO}

Lo scopo di questo studio è quello di paragonare l'efficacia della spirulina platensis e della cetirizina nel trattamento della rinite allergica $(A R)$. Questo trial clinico randomizzato controllato riguarda 53 pazienti affetti da AR, suddivisi in due gruppi, sperimentale e di controllo afferenti ad un centro terziario accademico accreditato. I pazienti del gruppo sperimentale sono stati trattati con Spirulina (2 g/die) mentre il gruppo controllo con cetirizina (10 mg/die) per due mesi. Sono stati valutati i pazienti attraverso un questionario standard sui sintomi e sui mediatori dell'infiammazione, prima e dopo il trattamento. Sono stati valutati 23 uomini e 30 donne con età media di 26,75 anni (SD 9,26; range 8-58). La differenza nei due gruppi in termini di età e genere non sono significative. Non è emersa differenza significativa fra $i$ due gruppi in termini di presentazione clinica prima della terapia $(P>0,05)$. La prevalenza della rinorrea $(P=0,021)$, ostruzione nasale $(P=0,039)$ e iposmia $(P=0,030)$ nel gruppo sperimentale è migliorata significativamente se paragonata al gruppo controllo, grazie alla terapia. La condizione di sonno, attività lavorativa giornaliera e attività sociale è migliorata nel gruppo sperimentale $(P<0,05)$. In più, non vi è alcuna differenza dopo 1 mese nei livelli di IL-1 fra i due gruppi per quanto riguarda i mediatori dell'infiammazione prima del trattamento; i livelli di interleuchina $(I L)-1 \alpha(P<0,001), I L-1 \beta$ $(P<0,001)$, e IL-4 $(P=0,008)$ sono significativamente più bassi nel gruppo sperimentale e quelli di IL-10 più alti. In conclusione, la Spirulina è più efficace della cetirizina nel trattamento dei sintomi della rinite allergica e può essere considerata una valida alternativa terapeutica.

PAROLE CHIVAE: rinite allergica, terapie, terapia medica della rinite allergica, spirulina
Received: March 2, 2019

Accepted: October 27, 2019

\section{Correspondence}

Mehdi Bakhshaee

Sinus and Surgical Endoscopic Research Center, Emmam Reza Hospital, Faculty of Medicine, Mashhad University of Medical Sciences, Mashhad, Iran Tel./Fax +985118413492

E-mail: bakhshaeem@mums.ac.ir

Funding

None.

Conflict of interest

The Authors declare no conflict of interest.

How to cite this article: Nourollahian M, Rasoulian B, Gafari A, et al. Clinical comparison of the efficacy of spirulina platensis and cetirizine for treatment of allergic rhinitis. Acta Otorhinolaryngol Ital 2020;40:224-229. https://doi. org/10.14639/0392-100X-N0139

() Società Italiana di Otorinolaringoiatria e Chirurgia Cervico-Facciale

\section{(c) (1) $\circledast$}

This is an open access article distributed in accordance with the CC-BY-NC-ND (Creative Commons Attribution-NonCommercial-NoDerivatives 4.0 International) license. The article can be used by giving appropriate credit and mentioning the license, but only for non-commercial purposes and only in the original version. For further information: https:// creativecommons.org/licenses/by-nc-nd/4.0/deed.en 


\section{Introduction}

The prevalence of allergic rhinitis (AR) is on the rise on a global scale, and has major impact affecting the quality of life in large populations. Based on various reports its prevalence in Asia ranges from 27\% in South Korea to 32\% in the United Arab Emirates ${ }^{1}$. According to the recent study in Iran, the prevalence of allergic rhinitis in Tehran (capital of Iran) and Mashhad (Northeast Iran) was reported to be $28.3 \%$ and $22.4 \%$, respectively ${ }^{2,3}$. The main medical procedure for treatment of AR involves the administration of antihistamines and corticosteroids, which mainly reduce the signs and symptoms of the disease ${ }^{4}$. However, the long-term intake of these medications can cause serious side effects for patients. Current therapeutic methods have failed to secure a definite treatment for AR, and the need for continuous medical treatment has raised concerns about side effects in patients. Therefore, alternative therapeutic options are required in this regard. The use of complementary and alternative medicine (CAM) has been a rising trend over the past decades. Given the increasing prevalence of $\mathrm{AR}$, it is necessary for ear, nose and throat (ENT) specialists, as well as other physicians involved in treating this condition, to manage CAM therapies used by patients ${ }^{5}$. Spirulina as one of the drugs used in CAM treatment of AR that is a type of blue-green algae that belongs to cyanobacteria and grown on a large scale. Few studies have investigated the effect of spirulina on control and management of AR. The use of spirulina has been widely commercialised as a nutritional supplement to balance the function of the immune system and as treatment for a range of diseases ${ }^{6}$. Today, spirulina is predominantly utilised as a nutritional supplement in the pharmaceutical industry in the form of pills or powder. The effect of spirulina on inflammatory mediators in human samples has been limited to the results of one study up to now ${ }^{7}$. To the best of our knowledge, no study has simultaneously examined the clinical and laboratory effects of spirulina. The aim of the present study was to determine the therapeutic effect of spirulina platensis on AR.

\section{Materials and methods}

This single-blind randomised clinical trial was carried out on 65 patients with persistent AR from October 2015 to March 2016. The allergic patients were those with clinical symptoms and signs of AR that showed a positive reaction to at least one allergen during a skin prick test. All of the participants had persistent allergic rhinitis. The usual pollen calendar in Iran is from May to July. However, by selecting an appropriate timeframe, we attempted to reduce the impact of seasonal factors on severity of allergic symptoms.

The effect of spirulina was investigated on the signs and symptoms of AR according to the visual analog scale (VAS). In addition, daily working, sleep condition and social activity of patients in both groups were assessed before and after the intervention based on VAS. Subjects were divided into two groups, namely the experimental and control groups with daily doses of $2 \mathrm{~g}$ spirulina and $10 \mathrm{mg}$ cetirizine both for 2 months, respectively.

Patients were randomly assigned to each group based on a simple randomisation method using a random number table. The symptoms were compared between the two groups before and after treatment. Informed consent was obtained from each participant prior to participating in the study. Moreover, the study protocol was approved by the Local Institutional Board with the ethics code of 940150 .

Patients with signs and symptoms of AR visiting either allergy or ENT clinics were enrolled in this study. A full medical history was taken, and thorough ENT examination was performed to confirm the clinical diagnosis of persistent AR and rule out other possible causes of rhinitis. Next, subjects underwent a skin prick test for the identification of common aeroallergens; accordingly, the diagnosis could be further confirmed by the presence of related antibodies.

All patients with systemic diseases, using anticoagulants or any drugs with anti-inflammatory effects, with an intolerance to the side effects of spirulina (e.g., nausea, constipation, and mild fever), using immunosuppressive drugs, with prior immunotherapy, using blood glucose or blood pressure controlling drugs, as well as pregnant or lactating women, and asthmatic patients were excluded.

\section{Sample size calculation}

In this study, the objective is to show that spirulina is at least as good as cetirizine as standard therapy in reducing the cardinal symptoms of AR. After assessing similar studies ${ }^{5}$ with a clinically significant effect of 0.4 or more over the 2 weeks, a two-sided significance of 0.05 and a power of 0.9 , a total of 26 participants would be required in each arm assuming a standard deviation of 0.51 and 0.55 . We anticipated a $15 \%$ percent withdrawal rate. Thus, the total primary sample size was considered to be 65 .

\section{Clinical assessment}

The overall discomfort experienced by the patients related to cardinal symptoms of rhinitis and factors related to the subjects' quality of life were recorded and compared after the intervention within and between groups. Clinical symptoms were recorded using a VAS for five cardinal rhinitis symptoms, including sneezing, nasal congestion, rhinorrhoea, smell disturbance and nasal itching. Furthermore, several factors related to patients' quality of life, including sleep condition, working life and social activity, were evaluated based on VAS. The symptoms were recorded according to patients' perception and scored from 0 to 5 (i.e., 0 and 5 indicative of no symptoms and the most severe symptoms, respectively). 


\section{Laboratory assessment}

Before and after intervention, all patients were referred to the immunology laboratory, and $5 \mathrm{ml}$ of blood was taken from each participant. Next, blood samples were centrifuged, and the serum was separated. The levels of interleukin (IL)-10, IL-4, IL-1 and interferon-gamma (IFN- $\gamma$ ) were measured using a microarray technique before and after treatment in both groups, and the results were compared.

\section{Statistical analysis}

The collected data were analysed using SPSS software (version 16). Due to the fact that the study was a randomised controlled clinical trial, the normality test was first checked and then an independent $\mathrm{t}$-test or paired t-test was used. The paired-sample t-test was utilised for intergroup comparisons. For subgroup analysis in each group, the t-test was used for assessing quantitative variables. In addition, a P-value less than
0.05 was considered statistically significant for all the abovementioned tests.

\section{Results}

In this randomised controlled clinical trial, 65 patients were enrolled among whom 11 were excluded due to a negative prick test or withdrawal from intervention. The remaining 53 participants were divided into the experimental $(n=26)$ and control $(n=27)$ groups. One patient in the experimental group was excluded due to the refusal to continue the treatment course. The mean age of participants was $26.75 \pm 9.26$ (mean $\pm \mathrm{SD}$ ) years (age range: $8-58$ ).

Based on statistical findings, no significant difference was observed between the two groups regarding age or gender (Fig. 1).

Results of VAS test showed that Salsala was identified as

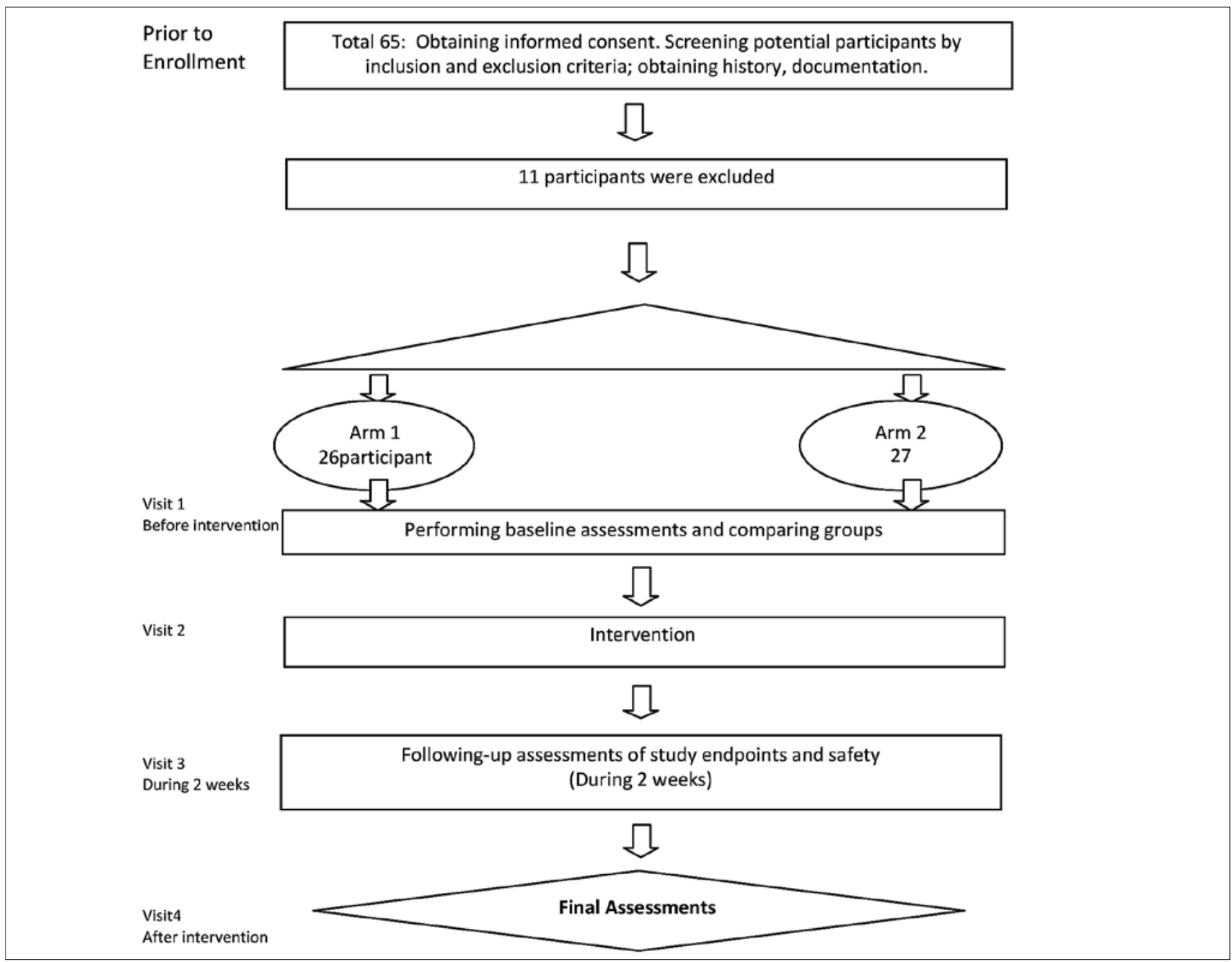

Figure 1. Enrolment of patients. 
the most common allergen among participants and the least prevalence was related to feather. Before treatment initiation, there was no difference in symptoms between the two groups (Tab. I). After the therapeutic course, improvement of symptoms was significantly higher in the experimental group than in the control group for all symptoms except nasal itching, sneezing, as well as and INF- $\gamma$.

The prevalence of rhinorrhoea $(\mathrm{P}=0.021)$, nasal congestion or obstruction $(\mathrm{P}=0.039)$ and loss of smell $(\mathrm{P}=0.030)$ were significantly lower in the experimental group than in the control group; however, no significant changes were observed regarding the prevalence of sneezing $(\mathrm{P}=0.096)$ and nasal itching $(\mathrm{P}=0.099)$ between the two groups. Sleep condition, working life and social activity improved in both groups, and the improvement was significantly higher in the experimental group. In addition, the levels of IL- $1 \alpha$ $(\mathrm{P}<0.001)$, IL-1 $\beta(\mathrm{P}<0.001)$ and IL-4 $(\mathrm{P}=0.008)$ were significantly lower in the spirulina group in comparison to those in the control group. (Tab. II).

Investigations showed that a reduction was observed in the severity of all symptoms in both groups after intervention (Figs. 2, 3) and these differences were significant for all factors in the spirulina group and for all factors in the cetirizine group except IL-1 $\beta(\mathrm{P}=0.109)$, IL-4 $(\mathrm{P}=0.078)$ and IL-10 (P = 0.68) (Tab. III).

\section{Discussion}

In the present study, based on intragroup evaluation, treatment resulted in a significant decrease in all rhinitis symptoms and improved the patients' quality of life. The use of

Table I. Comparison of cardinal allergic rhinitis symptoms in two groups before intervention.

\begin{tabular}{lcccc}
$\begin{array}{l}\text { Type } \\
\text { of symptoms }\end{array}$ & $\begin{array}{c}\text { Allergic rhinitis } \\
\text { symptoms }\end{array}$ & \multicolumn{2}{c}{ Treatment methods } & P-value \\
& Spirulina & Cetirizine & \\
Clinical & Nasal itching & $2.08 \pm 1.60$ & $2.37 \pm 1.25$ & 0.438 \\
presentation & Rhinorrhoea & $2.42 \pm 1.47$ & $2.48 \pm 1.22$ & 0.876 \\
& Nasal obstruction & $3.08 \pm 1.30$ & $3.59 \pm 1.57$ & 0.191 \\
& Sneezing & $2.31 \pm 1.12$ & $2.44 \pm 1.31$ & 0.686 \\
& Smell reduction & $2.96 \pm 1.89$ & $2.52 \pm 1.83$ & 0.389 \\
Quality of life & Sleep condition & $1.73 \pm 1.28$ & $1.48 \pm 1.40$ & 0.502 \\
factors & Daily working & $2.38 \pm 1.10$ & $2.85 \pm 1.56$ & 0.215 \\
& Social activity & $1.69 \pm 1.32$ & $1.96 \pm 1.43$ & 0.477 \\
Inflammatory & INF $\gamma$ & $1.56 \pm 2.38$ & $0.75 \pm 1.46$ & 0.07 \\
mediators & IL-1 $\alpha$ & $0.55 \pm 1.19$ & $0.18 \pm 0.28$ & 0.583 \\
& IL-1 $\beta$ & $0.84 \pm 1.15$ & $0.86 \pm 1.38$ & 0.795 \\
& IL-4 & $1.55 \pm 1.45$ & $1.24 \pm 0.57$ & 0.587 \\
& IL-10 & $1.3 \pm 1.05$ & $1.83 \pm 1.43$ & 0.135 \\
\hline
\end{tabular}

Data are reported as "mean \pm standard deviation"; significance level is 0.05 .
Table II. Comparison of cardinal symptoms of allergic rhinitis in the two groups after intervention.

\begin{tabular}{lcccc}
$\begin{array}{l}\text { Type } \\
\text { of symptoms }\end{array}$ & $\begin{array}{c}\text { Allergic rhinitis } \\
\text { symptoms }\end{array}$ & \multicolumn{2}{c}{ Group } & P-value \\
& Spirulina & Cetirizine & \\
Clinical & Nasal itching & $1.08 \pm 0.89$ & $1.52 \pm 1.01$ & 0.099 \\
presentation & Rhinorrhoea & $0.96 \pm 1.00$ & $1.63 \pm 1.04$ & $0.021^{*}$ \\
& Nasal obstruction & $1.46 \pm 0.95$ & $2.15 \pm 1.26$ & $0.039^{*}$ \\
& Sneezing & $0.96 \pm 0.72$ & $1.37 \pm 1.01$ & 0.096 \\
& Smell reduction & $0.81 \pm 0.9$ & $1.44 \pm 1.30$ & $0.030^{*}$ \\
Quality of life & Sleep condition & $0.77 \pm 0.59$ & $1.48 \pm 1.37$ & $0.018^{*}$ \\
factors & Daily working & $0.88 \pm 0.65$ & $1.56 \pm 1.31$ & $0.023^{*}$ \\
& Social activity & $0.50 \pm 0.58$ & $1.11 \pm 1.31$ & $0.034^{*}$ \\
Inflammatory & INF $\gamma$ & $0.47 \pm 0.75$ & $1.22 \pm 1.63$ & 0.583 \\
mediators & IL-1 $\alpha$ & $0.08 \pm 0.16$ & $0.56 \pm 0.49$ & $<0.001^{*}$ \\
& IL-1 $\beta$ & $0.08 \pm 0.27$ & $1.28 \pm 1.34$ & $<0.001^{*}$ \\
& IL-4 & $1.05 \pm 1.06$ & $1.64 \pm 0.79$ & $0.008^{*}$ \\
& IL-10 & $2.44 \pm 1.49$ & $1.7 \pm 1.17$ & $0.049^{*}$ \\
\hline
\end{tabular}

Data are reported as "mean \pm standard deviation"; significance level is 0.05 .

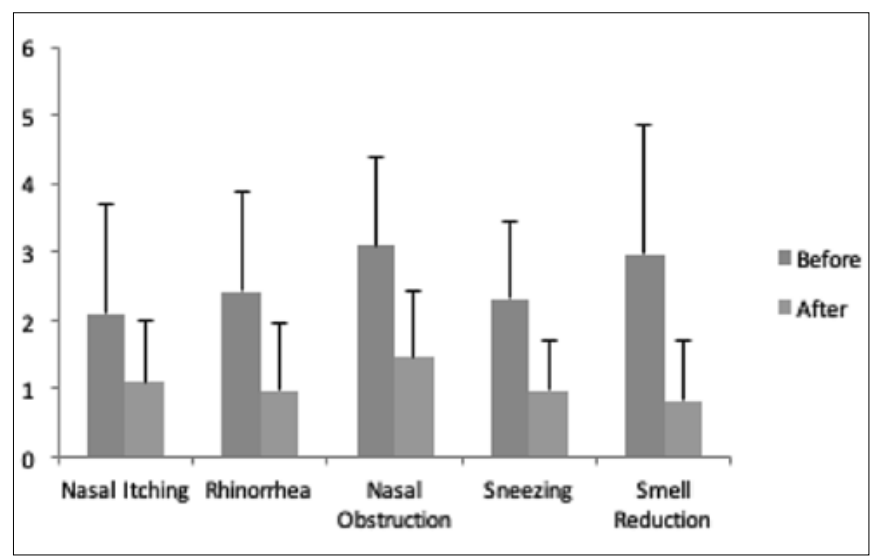

Figure 2. The effect of intervention on cardinal symptoms of allergic rhinitis in spirulina group.

spirulina was associated with significant improvement in the severity of most rhinitis symptoms, including rhinorrhoea, nasal congestion and smell disturbance. In addition, the quality of life in the experimental group enhanced significantly in comparison to that in the control group.

In the comparison between the two types of treatment, despite the fact that the levels of mediators were not different at the beginning of the study, the use of spirulina led to a significant decrease in the levels of IL- $\alpha$, IL- $\beta$ and IL4 , as well as a significant increase in the level of IL-10. According to the decreasing effect of spirulina on pro-inflammatory cytokines (e.g., IL- $\alpha$, IL- $\beta$, and IL-4) and the increasing effect on the immunosuppressive cytokine (i.e., IL-10), it seems that relief of symptoms may be due to the anti-inflammatory effects of this agent.

Mao et al. assessed the mechanism of spirulina on AR pa- 
Table III. Comparison of cardinal allergic rhinitis symptoms before and after intervention in separate groups.

\begin{tabular}{|c|c|c|c|}
\hline \multirow{2}{*}{$\begin{array}{l}\text { Type } \\
\text { of symptoms }\end{array}$} & \multirow{2}{*}{$\begin{array}{l}\text { Allergic rhinitis } \\
\text { symptoms }\end{array}$} & \multicolumn{2}{|c|}{ P-value } \\
\hline & & Spirulina & Cetirizine \\
\hline \multirow{5}{*}{$\begin{array}{l}\text { Clinical } \\
\text { presentation }\end{array}$} & Nasal itching & $<0.000^{\star}$ & $<0.000^{*}$ \\
\hline & Rhinorrhoea & $0.003^{*}$ & $<0.000^{*}$ \\
\hline & Nasal obstruction & $<0.000^{\star}$ & $<0.000^{\star}$ \\
\hline & Sneezing & $0.037^{\star}$ & $<0.000^{*}$ \\
\hline & Smell reduction & $<0.000^{\star}$ & $0.001^{*}$ \\
\hline \multirow{3}{*}{$\begin{array}{l}\text { Quality of life } \\
\text { factors }\end{array}$} & Sleep condition & $0.023^{*}$ & $0.012^{*}$ \\
\hline & Daily working & $0.003^{*}$ & $<0.000^{*}$ \\
\hline & Social activity & $0.016^{\star}$ & $0.043^{\star}$ \\
\hline \multirow{5}{*}{$\begin{array}{l}\text { Inflammatory } \\
\text { mediators }\end{array}$} & INF $\mathrm{Y}$ & $0.003^{\star}$ & $0.053^{*}$ \\
\hline & IL-1 $\alpha$ & $0.01^{*}$ & $0.005^{\star}$ \\
\hline & IL-1 $\beta$ & $0.005^{\star}$ & 0.109 \\
\hline & IL-4 & $<0.001^{\star}$ & 0.078 \\
\hline & IL-10 & $<0.001^{*}$ & 0.68 \\
\hline
\end{tabular}

Data are reported as "mean \pm standard deviation"; significance level is 0.05 .

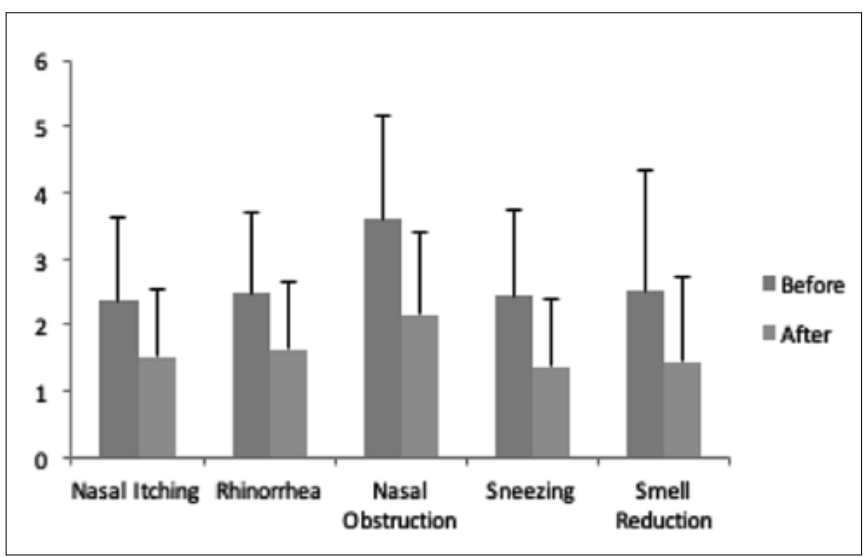

Figure 3. The effect of intervention on cardinal symptoms in the cetirizine group.

tients ${ }^{7}$. In this regard, they reported that daily consumption of $2,000 \mathrm{mg}$ spirulina decreases IL-4 levels by $32 \%$ in phytohemagglutinin-induced cells. These findings show that Spirulina can improve the $\mathrm{T}$ helper $(\mathrm{Th})$ profile by suppressing Th2 cell differentiation (which is mediated to some extent by suppressing the production of IL-4) in AR patients. The aforementioned study was the first human nutritional study to demonstrate the protective effects of spirulina on AR. The present study confirmed these positive findings from both clinical and laboratory aspects. The difference between the two studies is probably due to differences in the duration of treatment and follow-up periods. In the present study, patients were followed up for a shorter time; furthermore, the use of spirulina was compared with another standard treatment.

In a study by Cingi et al. (2008), the effects of spirulina were also studied on AR ${ }^{8}$. The results of a double-blind placebo-controlled study investigating the efficacy and tolerability of spirulina treatment on AR indicated a significant improvement in clinical symptoms, such as rhinorrhoea, sneezing, nasal itching and congestion in the spirulina group in comparison to the control group $(\mathrm{P}<0.001)$. Spirulina was clinically more efficient in treating AR compared with placebo. In the above-mentioned study, it was proposed that further studies are required to better clarify the mechanism of the mentioned effect. The findings of a study by Cingi et al. in terms of the efficiency of spirulina in controlling the symptoms of AR are consistent with the results of the present study. The mechanism of this effect was also surveyed by investigating the related cytokines; nevertheless, Cingi et al. only focused on the clinical effects of spirulina.

In a systematic review (2006), Karkos et al. examined the supplements commonly used in complementary medicine in the field of otolaryngology ${ }^{9}$. In this study, the evaluations were only conducted on clinical trials, and animal studies were not included. Three studies were observed regarding the effect of spirulina on allergy, rhinitis and immune response modulation.

One of the above-mentioned trials was a randomised doubleblind placebo-controlled study on AR patients, which showed the positive effects of spirulina dietary supplementation for 12 weeks. Although the other two were non-randomised studies, they reported the positive effects of spirulina on mucosal immunity. Karkos et al. concluded that there is acceptable evidence regarding the positive effects of spirulina on $\mathrm{AR}$, although further trials are required in this regard.

In addition to human studies, investigation in animal models have also examined the effect of spirulina platensis on IL-4 and IFN- $\gamma$ expression in the serum of a laboratory rat affected with AR ${ }^{10,11}$. They concluded that spirulina platensis is very effective in the treatment of AR through the regulation of IL-4 and IFN- $\gamma$ expression, as well as the adjustment of the imbalance in the Th1/Th2 cytokine network. These findings were also confirmed by a recent study that showed immulina exhibits anti-inflammatory properties and inhibits the release of histamine from mast cells ${ }^{12}$. The present study on the effect of spirulina on AR patients confirmed this effect on human beings.

There are a few major aspects of using spirulina, which further highlight the effectiveness of this intervention. Given the results of multiple studies performed on rodents, as well as the long and historical use of spirulina algae by humans, the Food and Drug Administration has approved the safety of spirulina ${ }^{13}$. Therefore, there are no concerns regarding the administration of spirulina.

On the other hand, in addition to the therapeutic applica- 
tion, spirulina can have invaluable effects as a nutritional and pharmaceutical supplement. In previous studies, it was shown that spirulina contains high levels of proteins, essential fatty acids, essential amino acids, micro- and macrominerals, vitamins and polysaccharides; in other words, it offers a favourable combination of all components required by the human body ${ }^{14-16}$.

It should be noted that considering the nature of AR and effect of exposure to allergens on the severity of clinical symptoms, the different environmental conditions of the two groups could have affected the results of the present study. However, by conducting a randomised trial and selecting an appropriate timeframe, we tried to reduce the impact of seasonal factors on the severity of allergic symptoms. One of the advantages of the present study was the laboratory assessment of patients by measuring inflammatory mediators; consequently, the mechanism of its effect could be judged more precisely.

Spirulina treatment has a principal downside in terms of the high dose required; a patient needs to take $2 \mathrm{~g}$ of spirulina equivalent in four daily capsules. In practice, many patients will resist taking such a high volume of medicine. Therefore, it is recommended to perform further studies with a longer follow-up period to investigate the effect of the drug on the relapse of clinical symptoms and ensure patients that there are no side effects of spirulina. Also, patients were regularly monitored for side effects during the study. However, more thorough studies are recommended to more accurately identify any potential side effects.

\section{Conclusions}

The use of spirulina seems to be more effective than the administration of cetirizine in improvement of both clinical presentations and inflammatory mediators of AR patients. Spirulina should be considered as an alternative treatment in patients with AR.

\section{References}

1 Chong SN, Chew FT. Epidemiology of allergic rhinitis and associated risk factors in Asia. World Allergy Organ J 2018;11:17. https://doi. org/10.1186/s40413-018-0198-z
2 Shoormasti RS, Pourpak Z, Fazlollahi MR, et al. The prevalence of allergic rhinitis, allergic conjunctivitis, atopic dermatitis and asthma among adults of Tehran. Iran J Public Health 2018;47:1749-55.

3 Varasteh AR, Fereidouni M, Shakeri MT, et al. Prevalence of allergic disorders among the population in the city of Mashhad, Northeast Iran. J Public Health 2009;17:107-12. https://doi.org/10.1007/ s10389-008-0217-6

4 Flint PW, Haughey BH, Niparko JK, et al. Cummings otolaryngology-head and neck surgery e-book: head and neck surgery. 3-Volume Set. Fifth edition. St Louis: Mosby; 2010.

5 Man LX. Complementary and alternative medicine for allergic rhinitis. Curr Opin Otolaryngol Head Neck Surg 2009;17:226-31. https:// doi.org/10.3760/cma.j.issn.1673-0860.2018.09.018

6 Gershwin ME, Belay A. Spirulina in human nutrition and health. Boca Raton: CRC Press; 2007. pp 18-21.

7 Mao TK, Van de Water J, Gershwin ME. Effects of a Spirulinabased dietary supplement on cytokine production from allergic rhinitis patients. J Med Food 2005;8:27-30. https://doi.org/10.1089/ jmf.2005.8.27

8 Cingi C, Conk-Dalay M, Cakli H, et al. The effects of spirulina on allergic rhinitis. Eur Arch Otorhinolaryngol 2008;265:1219-23. https:// doi.org/0.1007/s00405-008-0642-8

9 Karkos PD, Leong SC, Arya AK, et al. 'Complementary ENT': a systematic review of commonly used supplements. J Laryngol Otol 2007;121:779-82. https://doi.org/10.1017/S002221510600449X

10 Chen LL, Zhang SF, Huang DN, et al. Experimental study of spirulina platensis in treating allergic rhinitis in rats. Zhong Nan Da Xue Xue Bao Yi Xue Ban 2005;30:96-8.

11 Yang X-Y, Cheng L, XU J. Effect of spirulina platensis on expression of interleukin-4 and interferon- $\gamma$ in serum of experimental allergic rhinitis in rat. J Pract Med Techniques 2004;36.

12 Appel K, Munoz E, Navarrete C, et al. Immunomodulatory and inhibitory effect of Immulina ${ }^{\circledR}$, and Immunloges ${ }^{\circledR}$ in the Ig-E mediated activation of RBL-2H3 cells. A new role in allergic inflammatory responses. Plants (Basel) 2018;7:13. https://doi.org/10.3390/ plants7010013

13 Deng R, Chow TJ. Hypolipidemic, antioxidant, and antiinflammatory activities of microalgae Spirulina. Cardiovasc Ther 2010;28:e33-e45. https://doi.org/10.1111/j.1755-5922.2010.00200.x

14 Belay A. The potential application of Spirulina (Arthrospira) as a nutritional and therapeutic supplement in health management. J Am Nutraceutical Assoc 2002;5:27-48.

15 Habib MAB. A review on culture, production and use of Spirulina as food for humans and feeds for domestic animals and fish. Rome, Italy: Food and Agriculture Organization of the United Nations; 2008.

16 Karkos PD, Leong SC, Karkos CD, et al. Spirulina in clinical practice: evidence-based human applications. Evid Based Complement Alternat Med 2011;2011:531053. https://doi.org/10.1093/ecam/nen058 